\title{
Exploring the Contributions of School Belonging to Complete Mental Health Screening
}

\author{
Kathryn Moffa, ${ }^{1}$ Erin Dowdy ${ }^{1}$ and Michael J. Furlong ${ }^{2}$ \\ ${ }^{1}$ Counseling, Clinical, and School Psychology Department, University of California, USA \\ ${ }^{2}$ International Center for School-Based Youth Development, University of California, USA
}

\begin{abstract}
Considering the many positive outcomes associated with adolescents' sense of school belonging, including psychological functioning, it is possible that including an assessment of school belonging within a complete mental health screening process could contribute to the prediction of students' future mental health status. This exploratory study used complete mental health screening data obtained from a central California high school $(N=1,159)$. At Time 1 (T1) schoolwide screening was used to identify complete mental health groups by applying a dual-factor strategy and concurrently measuring students' school belonging. One year later at Time 2 (T2), social-emotional wellbeing and internal distress were assessed. Cross-sectional T1 results indicated that there were significant differences in school belonging between students who reported low global life satisfaction and those who reported average or high global life satisfaction, regardless of reported level of psychological distress. A comparison of T1 to T2 data revealed that global life satisfaction and psychological distress were predictive of wellbeing and internal distress. However, contrary to study expectations, school belonging at $\mathrm{T} 1$ added little to the prediction of T2 psychological distress beyond the information already provided by the T1 dual-factor screening framework. Implications for practice and future directions are discussed.
\end{abstract}

- Keywords: complete mental health, screening, school belonging

It is estimated that approximately one out of every three or four youths worldwide will meet the criteria for a formal mental health disorder in their lifetime (Costello, Mustillo, Keller, \& Angold, 2004). Considering that approximately half of all mental disorders have onset by 14 years of age (World Health Organization, 2014), it is important to be mindful of how to identify, treat, and prevent the onset of more debilitating symptoms in youth. Recognising the barriers to accessing private mental health care (e.g., geographic location, cost, and stigma), and coupled with findings that the vast majority of youths do not seek help for their symptoms in a timely manner (Christina et al., 2000), schools are ideal locations in which to implement efforts to prevent and

Received 26 April 2016; Accepted 16 May 2016; First published online 15 June 2016

Address for Correspondence: Michael Furlong, University of California Santa Barbara, Gevirtz School of Education, International Center for School-Based Youth Development, Santa Barbara, CA, USA 93106. Email: mfurlong@education.ucsb.edu. 
respond to youths' psychological distress (Manassis et al., 2010). This recommendation for school-based services is aligned with findings that many negative school-based outcomes are associated with psychological distress, including difficulties with social relationships, lack of initiative with schoolwork, and poor academic achievement (Fröjd et al., 2008). Robust research findings indicate that youths' feelings of school belonging: (a) can mitigate negative developmental outcomes (Lester, Waters, \& Cross, 2013), (b) protect against psychological distress (Gratis, 2013; Pittman \& Richmond, 2007; Sargent, Williams, Hagerty, Lynch-Sauer, \& Hoyle, 2002), and (c) are associated with a range of positive psychological and educational developmental outcomes (Allen \& Bowles, 2012). As such, it is possible that measuring school belonging as part of schoolwide mental health screening could contribute unique information in support of prevention and intervention strategies to improve adolescents' mental health. Though previous research indicates that school belonging is positively associated with academic achievement (Furrer \& Skinner, 2003) and positive mental health indicators (Pittman \& Richmond, 2007; Vieno, Perkins, Smith, \& Santinello, 2005), the potential additive predictive effects of students' school belonging when included within a school-based, universal, complete mental health screening framework has not been thoroughly investigated.

\section{Dual-Factor Approach To Screen For Complete Mental Health}

Expanding beyond a primarily deficit-focused approach, contemporary mental health screening has examined a combination of students' psychological distress and subjective wellbeing (Moore et al., 2015). This 'dual-factor' approach, which examines both positive and negative symptoms of mental health (Greenspoon \& Saklofske, 2001; Keyes, 2005; Suldo \& Schaffer, 2008), is aligned with current definitions of mental health as the state of being 'free of psychopathology and flourishing, with high levels of emotional, psychological, and social well-being' (Keyes, 2005, p. 539). Although there is not yet a consensus criteria for determining student membership in complete mental health groups, the majority of school-based studies to date have first sorted students by symptoms of high and low psychological distress, and then by high and low subjective wellbeing (Greenspoon \& Saklofske, 2001; Suldo \& Shaffer, 2008; Venning, Wilson, Kettler, \& Eliott, 2013), a process that creates four logical mental health groups (Kim, Furlong, Ng, \& Huebner, in press). By screening students for both positive and negative indicators of mental health, school support teams have an expanded picture of students, including which strengths might serve as protective factors in the future and improve developmental outcomes (Furlong, Dowdy, Carnazzo, Bovery, \& Kim, 2014). It is possible that the addition of other measures beyond those typically used for dual-factor complete mental health screening may provide an even more comprehensive picture of students' current and future mental health. Given the known benefits of school belonging to students' mental health (Pittman \& Richmond, 2007), this study focused on how information on students' sense of school belonging may inform complete mental health screening practices.

\section{Importance Of School Belonging To Youths' Mental Health}

School belonging has been defined in multiple ways, often operationalised by describing the item content of the scale used to measure the construct, and characterised by having overlapping content with similar school-belonging domain constructs, such as school connectedness, membership, bonding, engagement, satisfaction, and 
attachment (Furlong, Froh, Muller, \& Gonzalez, 2014). Specifically, school belonging has been defined as when students 'feel close to, a part of, and happy at school; feel that teachers care about students and treat them fairly; get along with teachers and other students, and feel safe at school' (Libbey, 2007, p. 52). School belonging has also been defined as the degree to which students are personally invested in their school, compliant with school rules and expectations, engaged in academic and extracurricular activities, and believe in school values (Kia-Keating \& Ellis, 2007). Similarly, McNeely, Nonemaker, and Blum (2002) asserted that school connectedness, a related term, is defined by feelings of belonging at school and being cared for by members of students' school communities, including other students, families, and school staff. Regardless of the specific definition employed, a strong sense of school belonging and other domain-related constructs has been associated with increased academic motivation and performance (Furrer \& Skinner, 2003); improved psychological functioning (Pittman \& Richmond, 2007); increased happiness, self-esteem, better coping skills, social skills, and social supports; and reduced loneliness and fewer truancies (Vieno et al., 2005). Lester and colleagues (2013) reported that low levels of school belonging are associated with aggressive and violent behaviours (Chapman, Buckley, Sheehan, Shochet, \& Romaniuk, 2011), criminal behaviour, gang membership, and substance use (Catalano, Osterle, Fleming, \& Hawkins, 2004).

When examining the impact of school belonging on adolescents' future mental health, there are inconsistencies in the strength of prediction of school belonging across grade levels and gender. A study by Shochet, Dadds, Ham, and Montague (2006) with Australian adolescents found that a measure of school connectedness: (a) negatively predicted depressive symptoms one year later for boys and girls, and anxiety symptoms one year later for girls; and (b) positively predicted general functioning one year later for boys. However, the same study found that mental health status at baseline did not predict later school connectedness, suggesting that students' school belonging-related beliefs might serve as a protective factor against future mental health concerns. In a related study, Lester and colleagues (2013) conducted a longitudinal study examining the relations between school connectedness, depression, and anxiety among Australian adolescents $(N=3,123)$ who were transitioning from primary to secondary schools. Results indicated that symptoms of anxiety and depression increased over time, while feelings of school connectedness decreased. By conducting cross-lagged models to investigate causal direction across time between connectedness, depression, and anxiety, Lester et al. (2013) found that school connectedness in primary school positively predicted connectedness in secondary school. Additionally, higher levels of school connectedness in primary school predicted lower feelings of anxiety in secondary school in both females and males. However, only females' feelings of school connectedness in primary school negatively predicted symptoms of depression later on in secondary school. Like the study carried out by Shochet and colleagues (2006), mental health in primary school did not predict later school connectedness after transitioning from primary to secondary school, reinforcing the hypothesis that early feelings of school connectedness, or belonging, may impact later psychological wellbeing (Lester et al., 2013). Given findings that school belonging and the domain-related construct, school connectedness, may positively predict later psychological functioning, it is worthwhile to further investigate the relationship between belonging and later mental distress. Knowledge of a student's level of school belonging might contribute to enhanced screening, particularly for those students 
who present with average levels of psychological distress but have low psychological strengths/assets.

\section{Current Study}

Previous research has focused on the predictive validity of school belonging on future mental health during the transition from primary to secondary school and from Grade 8 to 9 (Lester et al., 2013; Lester \& Cross, 2015; Shochet et al., 2006). However, results of these studies suggest inconsistencies in the strength of prediction of school belonging on positive and negative indicators of adolescents' future mental health across grade levels, particularly as adolescents near, and transition to, Grade 9 (Lester et al., 2013; Lester \& Cross, 2015; Shochet et al., 2006). Therefore, additional research is warranted to investigate how school belonging might be utilised to predict youth's future mental health after the transition to Grade 9 and through the high school years. Considering that onset of psychological problems typically occurs during late adolescence (Kessler et al., 2009), the present study examined school belonging in youth during high school. By examining students' sense of school belonging in high school, schools might gain information to further inform the scope and context of prevention and intervention strategies. Within the school context, it might be particularly important to assess for variables, such as school belonging, that can be more directly influenced by the school staff and are proximally related to school functioning. However, it is unclear if adolescents' levels of school belonging can predict important outcomes above and beyond screening measures used in a dual-factor, complete mental health screening context. The current study aimed to examine how information on school belonging might enhance the prediction of future psychological distress beyond what can be gleaned from complete mental health screening. Specifically, the study investigated two research questions:

RQ 1: Do adolescent complete mental health groups differ on their self-reported sense of school belonging?

RQ 2: Does school belonging predict adolescents' future social-emotional wellbeing and internal distress above and beyond measures used for complete mental health screening?

\section{Method}

\section{Participants}

Students attending a high school in central California completed annual, schoolwide screening surveys at the beginning (October) of the 2014-2015 (Time 1 [T1]) and 2015-2016 (Time 2 [T2]) school years. At T1, 1,867 students (88\% of enrolled students) completed the screening survey. Approximately one year later, the school conducted its annual screening survey and 1,159 students (62\% of the original sample) who completed the T1 survey also completed the survey at T2. For this subset of students, at T1, 38\% $(n=442)$ were in 9th grade, $35 \%(n=407)$ in 10th grade, and $27 \%(n=309)$ in 11 th grade. One student did not report grade level. Students' self-reported sociocultural group/ethnicity was as follows: $46.5 \%$ Latino/Hispanic ( $n$ $=539), 38.4 \%$ White $(n=445), 2.8 \%$ Asian $(n=32), 0.9 \%$ Black/African American 
$(n=10), 0.3 \%$ Native Hawaiian or Pacific Islander $(n=3), 0.4 \%$ American Indian or Alaskan Native $(n=5)$, and $10.6 \%(n=123)$ Mixed (two or more ethnicities selected). Two students did not report sociocultural group preference. Approximately $51 \%(n=583)$ of students identified as female, $48 \%(n=555)$ identified as male, and approximately $1 \%(n=10)$ reported another gender identification.

\section{Measures}

Complete mental health. Complete mental health was measured using a combination of life satisfaction (Brief Multidimensional Students' Life Satisfaction Scale [BMSLSS]; Seligson, Huebner, \& Valois, 2003) and psychological distress (selected items from the Strengths and Difficulties Questionnaire [SDQ]; Goodman, 1997) instruments.

Global life satisfaction at T1. The BMSLSS is a self-report measure to gauge overall life satisfaction and satisfaction with friends, family, self, school, and living environment (Seligson et al., 2003). Previous confirmatory factor analysis supported a one-factor structure with loadings ranging from .57 to .79 and adequate fit. Items were measured using a 5-point response option used by Bickman et al. (2007; $1=$ very dissatisfied to $5=$ very satisfied), with higher scores indicative of greater global life satisfaction. For the current study, the average of students' scores on the six items was used as the indicator of positive global life satisfaction within the dual-factor complete mental health framework. The measure had good internal consistency $(\alpha=.83)$ in the present sample.

Psychological distress at T1. Negative indicators of students' mental health were measured by using the self-report version of the SDQ (Goodman, 1997). The SDQ is a measure designed for 11- to 17-year-old adolescents that measures five factors: Emotional Problems, Conduct Problems, Hyperactivity, Peer Problems, and Prosocial Behaviour. Previous analyses found that the internal consistency and factorial invariance for the five-factor model are not adequate (Rushkin, Jones, Vermeiren, \& Schwab-Stone, 2008; Stevanovic et al., 2015); hence, Rushkin and colleagues (2008) conducted a confirmatory factor analysis and found support for a three-factor structure: behavioural reactivity/conduct problems, emotional distress/withdrawal, and prosocial behaviour. Drawing from the Rushkin et al. (2008) study and with an interest to maintain survey efficiency, this study used the five items with the highest loadings from the behavioural reactivity/conduct problems (original SDQ items 2, 5, 10, 15, and 22; loadings .56 to .62) and emotional distress/withdrawal (original SDQ items 3, $6,8,13$, and 16 ; loadings .47 to .60) factors. Items were measured on a 3 -point scale ( 0 $=$ not true, $1=$ somewhat true, and $2=$ certainly true), with higher scores indicating more distress. Within the dual-factor complete mental health model, students' mean scores on these 10 items were used to determine students' psychological distress levels. Cronbach's alpha indicated adequate internal consistency among the 10 items with the present sample $(\alpha=.79)$.

School belonging at T1. Five items from the School Satisfaction subscale of the Multidimensional Students' Life Satisfaction Scale (MSLSS; Huebner, 1994; Huebner, Laughlin, Ash, \& Gilman, 1998) were used to assess students' feelings of belonging to school at T1. The original subscale consists of eight items and was previously used by Antaramian, Huebner, Hills, and Valois (2010) to measure students' 
feelings of belonging to their school and having strong relationships with teachers and peers. For the current study, the three reverse-keyed items were not used because previous research indicated that students in Grades 7-12 experienced difficulties with the items that were worded negatively (Sawatzky, Ratner, Johnson, Kopec, \& Zumbo, 2009): 'I wish I didn't have to go to school', 'There are many things about school I don't like', and 'I feel bad at school. The five items used in the present study were: 'I learn a lot at school', 'I look forward to being in school', 'I like being in school', 'School is interesting' and 'I enjoy school activities'. These items asked about the emotional and behaviour engagement aspects of school belonging and are similar to item content in the Psychological Sense of School Membership Scale (You, Ritchey, Furlong, Shochet, \& Boman, 2011) and the School Connectedness Scale (Furlong, O’Brennan, \& You, 2011). Students responded using a Likert-scale format indicating how much they agreed or disagreed with each item $(1=$ strongly disagree to $6=$ strongly agree), with higher scores representing higher levels of selfreported school belonging. The alpha coefficient for the five-item version in this study was .87.

Social emotional wellbeing at T2. The Social Emotional Health Survey - Secondary (SEHS-S) is a 36-item self-report measure that assesses youths' strengths (Furlong, You, Renshaw, Smith, \& O’Malley, 2014). Confirmatory factor analyses and invariance testing across multiple groups by You, Furlong, Felix, and O’Malley (2015) suggest a higher order-factor structure, with 12 subscales loading onto four second-order traits of Belief-in-Self (self-awareness, persistence, self-efficacy), Belief-in-Others (school support, family coherence, peer support), Emotional Competence (empathy, selfcontrol, behavioural self-control), and Engaged Living (gratitude, zest, and optimism). The second-order traits load onto a higher-order latent trait called Covitality. Other than the gratitude and zest subscales, students report their degree of functioning using a 4 -point scale $(1=$ not at all true of me and $4=$ very much true of me). Students report gratitude and zest on a 5 -point scale $(1=$ not at all and $5=$ extremely). The overall higher-order covitality score was used in this study as a measure of social-emotional wellbeing. Evidence for the higher-order invariance model has been provided across multiple, diverse samples including U.S. (You et al., 2015), Australian (Pennell, Boman, \& Mergler, 2015), Korean (Lee, You, \& Furlong, 2015), and Japanese (Ito, Smith, You, Shimoda, \& Furlong, 2015) samples. For this sample, the internal consistency for the overall covitality score was .88.

Internal distress at T2. Students' internal symptoms of psychological distress at T2 were measured with a seven-item scale designed for this study that examined symptoms of anxious and depressed emotional experiences. Items were measured using a 5 -point response scale $(1=$ not at all true of me to $5=$ very true of $m e)$ and asked students to report on their 'past month' experiences. The items were as follows: 'I had a hard time breathing because I was anxious', 'I worried that I would embarrass myself in front of others', 'I was tense and uptight', 'I had a hard time relaxing', 'I felt sad and down', 'It was hard for me to cope and I thought I would panic', and 'I was scared for no good reason'. Using the present study's sample, we completed maximum likelihood confirmatory factor analyses using MPlus (Muthén \& Muthén, 1998-2013). A two-factor model (anxious items and depression items) did not have adequate fit. The one-factor model (labelled Internal Distress) with seven items was 
supported by parallel analysis with factor loadings between .62 and .85 , and adequate fit, $\mathrm{CFI}=.97, \mathrm{SRMR}=.03$. To provide additional verification, the one-factor model was evaluated using an independent sample of students attending a high school in an urban California community located more than 300 kilometres from the present study's primary high school. This measurement verification sample had 71 females, 140 males, and one person who reported another gender identification. There were $69 \%$ th grade and 31\% 10th-grade students. The fit indices for this verification sample for the one-factor CFA were: CFI $=.94$, SRMR $=.04$. The internal consistency among the seven internal distress items was high $(\alpha=.90)$ for the current sample.

\section{Procedure}

Survey administration. Students completed screening surveys annually, in the fall (October) of the 2014-2015 (T1) and 2015-2016 (T2) school years. Measures used at $\mathrm{T} 1$ included an assessment of global life satisfaction, psychological distress, and school belonging. T2 included a measure of social-emotional wellbeing and internal distress. Surveys were administered in classroom units by regular classroom teachers following a prepared script.

Complete mental health groups. Following the T1 screening, complete mental health groups were created by first categorising students by low, average, and high levels of life satisfaction (BMSLSS) as suggested by Kim et al. (in press). Consistent with earlier complete mental health research, students were also categorised by normative and elevated levels of psychological distress (using 10 items from the SDQ; Greenspoon \& Saklofske, 2001; Suldo \& Shaffer, 2008). Similar to Kim, Dowdy, and Furlong (2014), $z$ scores for both overall life satisfaction and psychological distress were utilised to sort students into groups. Standardised scores for BMSLSS mean scores were generated to classify students according to three levels of global life satisfaction: high ( $z$ score greater than 1.0), average ( $z$ score between -1.0 and 1.0), and low ( $z$ score below -1.0 ). Next, standardised scores for the mean of the 10 SDQ items were generated to classify students according to two levels of distress: elevated ( $z$ score of 1.0 or greater) and normative ( $z$ score below 1.0; we use the term normative distress, recognising that many students experience some distress at subsyndromal levels as part of normal life experiences). Following Moore et al.'s (2015) recommendation to consider the number of students to whom a school can realistically provide intervention services, six complete mental health groups were created by logically crossing life satisfaction and distress scores (see Table 1):

1. high life satisfaction and normative distress

2. high life satisfaction and elevated distress

3. average life satisfaction and normative distress

4. average life satisfaction and elevated distress

5. low life satisfaction and normative distress

6. low life satisfaction and elevated distress.

Students traditionally labelled 'troubled' in complete mental health research were categorised as low life satisfaction and elevated distress, which is the primary triage target group of schoolwide mental health screening; that is, students reporting 
TABLE 1

Mean School Belonging (School Satisfaction Scale) Item Scores for Complete Mental Health Groups at Time 1

\begin{tabular}{|c|c|c|c|c|}
\hline Group & M & $S D$ & $n$ & $\%$ \\
\hline 1. Low Life Satisfaction, Elevated Distress & 3.60 & 1.05 & 45 & 3.9 \\
\hline 2. Low Life Satisfaction, Normative Distress & 3.65 & 0.94 & 101 & 8.7 \\
\hline 3. Average Life Satisfaction, Elevated Distress & 4.00 & 0.85 & 89 & 7.7 \\
\hline 4. Average Life Satisfaction, Normative Distress & 4.49 & 1.05 & 691 & 41.6 \\
\hline 5. High Life Satisfaction, Elevated Distress ${ }^{1}$ & 4.53 & 1.52 & 9 & .8 \\
\hline 6. High Life Satisfaction, Normative Distress & 5.09 & 0.63 & 225 & 19.4 \\
\hline
\end{tabular}

Note: ${ }^{1}$ Not included in data analyses due to small subgroup size.

high levels of distress and low levels of personal and/or social assets. Students that traditionally fall into the 'languishing' or 'vulnerable' group were categorised as low life satisfaction and normative distress, which is a group of students that is missed by traditional deficit-bounded mental health screening surveys.

\section{Data Analysis Plan}

Students who participated in screening at T1 and T2 were included in data analysis for the current study. To answer the first research question, analysis of variance (ANOVA) with planned contrasts was performed using SPSS version 22 to analyse whether mean levels of $\mathrm{T} 1$ school belonging differed across complete mental health groups. Students in the counterintuitive group reporting high life satisfaction and elevated distress $(n=9)$ were removed from analysis due to small sample size. Planned contrasts were utilised to compare the low life satisfaction and normative distress group to all other complete mental health groups. Assumptions of normality and homogeneity of variance were considered prior to conducting the ANOVA. Assumption of normality was violated, as the Kolmogorov-Smirnov test of normality was significant for four of the five mental health groups. However, it is recommended that sample sizes of 30 participants and above move forward with analyses (Pallant, 2013). Assumption of homogeneity was also violated, so Welch and Brown-Forsythe tests of equality of means were interpreted to determine differences across groups (Pallant, 2013).

To answer the second research question, two hierarchical multiple regressions were performed to evaluate the increase in explained variance of social-emotional wellbeing and internal distress at $\mathrm{T} 2$ when school belonging at $\mathrm{T} 1$ was added as an independent variable. First, mean scores on the global life satisfaction and the psychological distress measures at T1 were entered as independent variables in block 1 to predict social-emotional wellbeing at T2, which was measured by individuals' total scores on the SEHS-S. Next, mean scores on school belonging at T1 were entered into block 2 to examine the added value in screening for school belonging to predict future social-emotional wellbeing. The same process was completed to predict future internal distress, which was represented by scores on an independent measure of internal distress.

Assumptions of linearity, independence of errors, normality of residuals, absence of multicollinearity, absence of univariate and multivariate outliers, and homoscedasticity were considered prior to conducting the hierarchical multiple regressions. 
Originally, 18 multivariate outliers were identified (Mahalanobis distance > 16.26). Nine outliers were removed from analysis, as they fell into the high life satisfaction and elevated distress group that was removed when conducting the ANOVA. Two students categorised in the average life satisfaction and normative distress group were removed, since inconsistent item responses suggested that some responses might have not reflected their life satisfaction and distress at the time (see Furlong, Fullchange, \& Dowdy, in press). Finally, the remaining seven multivariate outliers were retained because they were categorised into the low life satisfaction and normative distress, and low satisfaction and elevated distress groups, indicating that these students are important to consider when examining prediction of social-emotional wellbeing and internalising symptoms of distress. Thirteen univariate outliers were identified, standardised residual $>3.0$, but Cook's Distance indicated that no cases posed potential problems, Cook's Distance $<1.00$ (Tabachnick \& Fidell, 2013). Thus, 1,148 students were included in regression analyses. After removal of outliers, all other assumptions were met when predicting social-emotional wellbeing. Although distribution of scores on the internal distress measure appeared to violate assumptions of normality and homoscedasticity, skewness and kurtosis indicated that data were slightly positively skewed, which was expected on a measure of distress, in which higher scores indicate more distress. With a sample of more than 1,000 students, all analyses conducted for this study had sufficient power to detect a small $\left(d=.30, f^{2}=.02\right)$ effect size.

\section{Results}

\section{Comparison of School Belonging Across Complete Mental Health Groups}

First, complete mental health groups were created for students who participated in universal screening at T1. Consistent with prior studies forming complete mental health groups among high school students (e.g., Antaramian et al., 2010; Suldo \& Shaffer, 2008), the two highest proportion of students were categorised as either having average life satisfaction and normative distress $(41.6 \%)$ or high life satisfaction and normative distress $(19.4 \%)$. Both of these groups would be considered to have 'complete mental health' in previous dual-factor research (e.g., Suldo \& Shaffer, 2008). Of particular interest in this study, at T1, there were $101(8.7 \%)$ students who had normative distress but also low life satisfaction, which is the group of students that is missed by traditional deficit focused mental health screeners. Descriptive statistics and correlations among the study variables are presented in Table 2.

Research question 1: Comparing school belonging among complete mental health groups at T1. To answer the first research question, mean level of school belonging was compared across complete mental health groups. Table 1 indicates that the group characterised by low life satisfaction and elevated distress had the lowest mean score for school belonging, followed by low life satisfaction and normative distress. Students who reported high life satisfaction, regardless of psychological distress level, reported the highest sense of school belonging (see Table 1). Since previous research indicates that there is a need for schools to address students in the low life satisfaction and normative distress group, mean school belonging scores for students in this group were compared to all other groups. Results indicate that there were significant differences 
TABLE 2

Variable Descriptive Statistics and Correlations Among Study Variables

\begin{tabular}{lrrrrrrr}
\hline Variable & 1 & 2 & 3 & 4 & 5 & $M$ & $S D$ \\
\hline 1. BMSLSS (Time 1) & - & & & & & 4.17 & .64 \\
2. SDQ - 10 items (Time 1) & $-.49^{*}$ & - & & & & .50 & .37 \\
3. School belonging (Time 1) & $.54^{*}$ & $-.32^{*}$ & - & & & 4.46 & .92 \\
4. SEHS-S (Time 2) & $.51^{*}$ & $-.33^{*}$ & $.41^{*}$ & - & & 116.41 & 16.92 \\
5. Internal distress (Time 2) & $-.33^{*}$ & $.47^{*}$ & $-.15^{*}$ & $-.34^{*}$ & - & 1.85 & .90 \\
\hline
\end{tabular}

Note: BMSLSS = Brief Multidimensional Life Satisfaction Scale (range 1-5). SDQ = Strengths and Difficulties Questionnaire (range 0-2). SEHS-S = Social and Emotional Health Survey - Secondary (range 26-15). School belonging was measured with the School Satisfaction Subscale of the Multidimensional Students' Life Satisfaction Scale (range 1-6). Internal distress (range 1-5).

$* p<.01$.

between groups, Welch test $(4,187.19)=83.63, p<.001$, and Brown-Forsythe test $(4,262.95)=55.53, p<.001$. There was a large effect size, eta ${ }^{2}=.20$, and post hoc analysis indicated that statistical power to detect this effect size was high (1.00). When comparing school belonging of the low life satisfaction and normative distress ('languishing') group to all other groups, means were significantly different in all contrasts other than when comparing to the low life satisfaction and elevated distress ('troubled') group, $F(1,77.13)=.05, p=.82$. Results suggest that students who reported low life satisfaction also reported the lowest sense of school belonging compared to their peers, regardless of psychological distress level.

\section{Research question 2: Prediction of social-emotional wellbeing and internal distress at} T2. First, T1 life satisfaction and psychological distress (which were used to create complete mental health groups) were entered as predictors of T2 social-emotional wellbeing in a linear regression analysis across the sample, $N=1,148$. Standardised coefficients were used to compare contributions of each independent variable (Pallant, 2013). The overall model was statistically significant, $F(2,1146)=209.23, p<.001, R^{2}$ $=.27$. Life satisfaction scores positively predicted social-emotional wellbeing scores, beta $=.46, p<.001$. Psychological distress scores negatively predicted social-emotional wellbeing scores: beta $=-.11, p<.001$. Next, life satisfaction and psychological distress (block 1), and school-belonging (block 2) from T1 were entered as predictors of T2 social-emotional wellbeing in a hierarchical regression analysis. The overall model was statistically significant, $F(3,1145)=157.64, p<.001, R^{2}=.29$. Scores on life satisfaction still positively predicted social-emotional wellbeing scores: beta $=.36, p$ $<.001$. Psychological distress scores negatively predicted social-emotional wellbeing scores: beta $=-.09, p=.001$. The addition of T1 school belonging mean item scores significantly contributed to the prediction of social-emotional wellbeing one year later: beta $=.19, p<.001$. Results indicated that the addition of school belonging had a small effect size, Cohen's $f^{2}=.035$. The post hoc power analysis revealed that the statistical power for detecting this effect size was .99 .

The same regression procedures were followed for internal distress. First, the T1 life satisfaction and psychological distress mean scores were entered as predictors of T2 internal distress in a linear regression analysis across the sample. The overall model was statistically significant, $F(2,1146)=175.56, p<.001, R^{2}=.24$. Global life satisfaction scores negatively predicted internal distress: beta $=-.14, p<.001$. Psychological 
distress scores positively predicted internal distress: beta $=.40, p<.001$. Next, mean item scores of T1 school belonging were added in block 2 of a hierarchical linear regression. The overall model was statistically significant, $F(3,1145)=119.84, p<$ $.001, R^{2}=.24$. Life satisfaction still negatively predicted internal distress: beta $=-.18, p$ $<.001$. As expected, psychological distress positively predicted internal distress scores: beta $=.41, p<.001$. The addition of school-belonging scores positively predicted $\mathrm{T} 2$ internal distress: beta $=.08, p=.010$, but the explained variance in internal distress was not substantial, Cohen's $f=.006$. For this observed negligible effect size, the achieved power was not adequate (.75); however, for this analysis with power $=.80$, a sample size of only 395 would be needed to detect a small effect size (e.g., $f=.02$ ).

\section{Discussion}

The aims of the current study were to investigate students' sense of school belonging in a complete mental health, schoolwide screening context, as well as to examine the added contribution that screening for school belonging might provide in predicting social-emotional wellbeing and internal distress. The results of this study provide insight into understanding students beyond their level of psychological risk and can aid schools in making more informed decisions about prevention and intervention strategies.

First, the study aimed to identify significant differences in students' sense of school belonging based on complete mental health group categorisation. As predicted, students who fell into the high life satisfaction and normative distress ('thriving') group reported the highest sense of school belonging, while students categorised by low life satisfaction and elevated distress ('troubled') reported the lowest sense of school belonging. However, further analysis found that reported levels of school belonging were not significantly different between the traditionally 'troubled' group and low life satisfaction and normative distress, or those students identified as 'languishing. These students reported significantly lower feelings of school belonging than students who reported average and high levels of life satisfaction. Similar results were found by Antaramian and colleagues (2010), in which students identified as 'vulnerable' had similar levels of risk for academic and behavioural issues, including low levels of school belonging, as those who were identified as 'troubled'. Furthermore, differences in school belonging across groups indicated a large practical significance, which suggests that school support teams may consider school belonging to be a differentiating factor among complete mental health groups, especially between students reporting low levels of life satisfaction and those reporting average and high levels. With this knowledge, schools can better address the needs of students reporting low life satisfaction and low distress, a group not typically identified in traditional screening approaches. Considering the negative outcomes associated with low levels of school belonging, including increased externalising behaviours (Chapman et al., 2011) and internalising symptoms of psychological distress (Lester et al., 2013), prevention and intervention strategies aimed at bolstering students' belonging and connections to school may be valuable.

The second aim of the current study was to examine the utility of students' school belonging in predicting longitudinal outcomes, particularly social-emotional wellbeing and internal distress one year later. Since high levels of school belonging are associated with improved psychological functioning (Pittman \& Richmond, 2007), 
increased happiness and social supports, and reduced loneliness (Vieno et al., 2005), we anticipated that school belonging at T1 would increase the variance explained when predicting social-emotional wellbeing and internal distress at T2. First, the study focused on the amount of variance in students' T2 social-emotional wellbeing explained by students' T1 life satisfaction and psychological distress symptoms. Together, life satisfaction and psychological distress symptoms (typically assessed during a complete mental health screening) explained $27 \%$ of the variance in socialemotional wellbeing one year later. A 1 standard deviation increase in life satisfaction predicted an increase in social-emotional wellbeing by 0.46 of a standard deviation. In contrast, an increase in psychological distress symptoms by 1 standard deviation was predicted to decrease T2 social-emotional wellbeing by only 0.11 of a standard deviation. This further supports complete mental health screening inclusive of both assets and distress symptoms, as life satisfaction predicted a larger change in social-emotional wellbeing one year later than students' psychological symptoms of distress.

When students' school belonging at T1 was added as a predictor of social-emotional wellbeing, explained variance modestly increased to $29 \%$. This time, a 1 standard deviation increase in life satisfaction, psychological symptoms, and school belonging was associated with a change in social-emotional wellbeing of $0.36,-0.09$, and 0.19 standard deviations, respectively. Although the explained variance was significant, it is important for schools to consider whether a small increase in explained variance warrants the resources to include a screening measure in high school that focuses on school belonging. Lester and Cross (2015) found that school connectedness was a significant predictor of psychological wellbeing at the end of primary school and for the first two years of secondary school. However, peer support was the most significant protective factor against anxiety and depression at the end of the second year of secondary school, while school safety served as a protective factor against stress. Based on the results of the ANOVA on the complete mental health groups, schools may be able to predict that students with low life satisfaction may be experiencing lower school belonging than their peers, allowing administration and staff to implement strategies that bolster school belonging. Information on the differences in school belonging may help inform intervention efforts.

Next, the study focused on predicting T2 internal distress. Life satisfaction and psychological distress symptoms at T1 explained almost $24 \%$ of the variance in internal distress, with school belonging only adding $0.4 \%$ to the explained variance. Although the addition of school belonging as a predictor was significant, a 1 standard deviation increase in school belonging only predicted a change in internal distress of 0.08 standard deviations. Furthermore, the results indicated that an increase in school belonging was associated with a slight increase in internal distress one year later, which is contradictory to prior research (Lester et al., 2013). It is possible that by high school, school belonging is not associated with change in students' internal distress over time. Although Lester and colleagues (2013) found that school connectedness predicted symptoms of depression and anxiety one year later for students transitioning to secondary school, this relation was particularly strong when examining the utility of school connectedness in primary school to predict depression and anxiety in Grades 8 and 9. This suggests that a sense of school belonging may have been instilled in students prior to entering high school, and those feelings from primary school can have significant impacts on later psychological distress. 
Engaging in complete mental health screening requires a planned, organised implementation by a school student care team inclusive of various members dedicated to enhancing school-based mental health services. Identifying and clarifying the goals for screening, carefully selecting instruments for use, involving key stakeholders, and attending to the process for prevention and intervention planning following the screening may help assuage concerns that are often associated with mental health screening, including concerns of stigma, insufficient resources, and inadequate measures (Moore et al., 2015). A core principle of using a complete mental health screening approach is that the results should potentially have meaning and utility for all students. While the results of this study suggested that a measure of school belonging did not contribute substantially to the prediction of later psychological distress, this does not imply that there are not benefits to schools regularly including belonging item content in schoolwide screeners, as belonging is an indicator of positive youth development and is associated with positive school climate. When engaging in complete mental health screening, school care teams will want to be mindful to include information that will be useful when planning school-based mental health services to support the continued development and thriving of their students.

\section{Limitations and Future Directions}

The current study incurred limitations that future research may consider when examining school belonging within a complete mental health screening framework. Significant limitations were found in the measures used to operationalise the variables of interest. Similar to Antaramian et al. (2010), this study operationalised school belonging by employing items from a widely used school satisfaction scale. However, it is possible that other screening tools that explicitly measure other aspects of school belonging and connectedness might prove to be stronger longitudinal predictors of wellbeing and distress. Additionally, although a one-factor structure of the internal distress measure developed for this study was adequate for the current sample and replicated with a small second independent sample, future research should confirm psychometric properties on an independent sample prior to conducting further analyses. Finally, additional research is needed on the modified version of the SDQ that was used in the current study. Although it was important to include brief measures for use in this schoolwide screening, further examination into the psychometric properties of the measures used in this study is warranted, and future research conducted with other measures of similar constructs may yield different results.

Although cut points for complete mental health groups were empirically based, the criteria used were still chosen based on the applicability to the study's sample and school, rather than established criteria that is applied to all complete mental health contexts. Other contemporary approaches to classifying students' mental health status that have employed latent class analysis (e.g., Kim, Dowdy, Furlong, \& You, 2016) may provide further insight into how school belonging is meaningfully differentiated among complete mental health groups. Future research should also examine the value of screening for school belonging to predict other outcomes, especially academic achievement. Finally, all assumptions prior to regression analyses were not met when looking at explained variance of high school students' internal distress. Based on the proportion of our sample in each complete mental health group, it is not expected that scores on the internal distress measure would be normally distributed. Still, violations 
of normality and homoscedasticity may have contributed to the unexpected positive relation between school belonging and internal distress.

Further research is needed to investigate differences in school belonging within and between complete mental health groups based on sociocultural groups, nationality, gender, and grade level, as meaningful differences could inform school prevention and intervention practices. Schools can also benefit from future research that examines the added utility of incorporating a measure of school belonging into screening at the primary school level, as results suggest that school belonging may not be associated with changes across time in high school. Future research may benefit from a focus on interventions that have an impact on students' sense of school belonging to investigate the effect of intervention on stability of complete mental health groups over time. When considering the significant differences in school belonging across groups, as well as previous research that suggests the 'languishing' group is the least stable across time (Kelly, Hills, Huebner, \& McQuillin, 2012), interventions that target school belonging may foster student strengths, leading to increased life satisfaction and social-emotional wellbeing.

\section{Acknowledgments}

None.

\section{Financial Support}

This research received no specific grant from any funding agency, commercial, or not-for-profit sectors.

\section{Conflicts of Interest}

None.

\section{Ethical Standards}

The authors assert that all procedures contributing to this work comply with the ethical standards of the relevant national and institutional committees on human experimentation and with the Helsinki Declaration of 1975, as revised in 2008. The research protocol was reviewed by and approved by the authors' human subjects institutional review board.

\section{References}

Allen, K.A., \& Bowles, T. (2012). Belonging as guiding principle in the education of adolescents. Australian Journal of Educational \& Developmental Psychology, 12, 108-119.

Antaramian, S.P., Huebner, E.S., Hills, K.J., \& Valois, R.F. (2010). A dual-factor model of mental health: Toward a more comprehensive understanding of youth functioning. American Journal of Orthopsychiatry, 80, 462-472. doi:10.1111/j.1939-0025.2010.01049.x

Bickman, L., Reimer, M., Lambert, E.W., Kelley, S.D., Breda, C., Dew, S., Vides de Andrade, A.R. (2007). Manual of the Peabody Treatment and Progress Battery (Electronic version). Nashville, TN: Vanderbilt University. http://peabody.vanderbilt.edu/ptpb/ 
Catalano, R., Oesterle, S., Fleming, C., \& Hawkins, D. (2004). The importance of bonding to school for healthy development: Findings from the Social Development Research Group. Journal of School Health, 74, 252-261. doi:10.1111/j.1746-1561.2004.tb08281.x

Chapman, R., Buckley, L., Sheehan, M., Shochet, I., \& Romaniuk, M. (2011). The impact of school connectedness on violent behavior, transport risk-taking behavior, and associated injuries in adolescence. Journal of School Psychology, 49, 399-410. doi:10.1016/j.jsp.2011.04.004

Christina, J.M., Gilman, S.E., Guardino, M., Mickelson, K., Morselli, P.L., Olfson, M., \& Kessler, R. (2000). Duration between onset and time of obtaining initial treatment among people with anxiety and mood disorders: An international survey of members of mental health patient advocate groups. Psychological Medicine, 30, 693-703. doi:10.1017/S0033291799002093

Costello, E.J., Mustillo, S., Keller, G., \& Angold, A. (2004). Prevalence of psychiatric disorders in childhood and adolescence. In B.L. Levin, J. Petrila, \& K.D. Hennessy (Eds.), Mental health services: A public health perspective (2nd ed., pp. 111-128). Oxford, UK: Oxford University Press.

Fröjd, S.A., Nissinen, E.S., Pelkonen, M.U.I., Marttunen, M.J., Koivisoto, A-M., \& Kaltiala-Heino, R. (2008). Depression and school performance in middle adolescent boys and girls. Journal of Adolescence, 31, 485-498. doi:10.1016/j.adolescence.2007.08.006

Furlong, M., Dowdy, E., Carnazzo, K., Bovery, B., \& Kim, E. (2014). Covitality: Fostering the building blocks of complete mental health. Communique, 42, 28-29.

Furlong, M., Froh, J., Muller, M., \& Gonzalez, V. (2014). The role of student engagement in engaged living and psychological and social well-being: The centrality of connectedness/relatedness. In D.J. Shernoff \& J. Bempechat (Eds.), National Society for the Study of Education yearbook — Engaging youth in schools: Empirically-based models to guide future innovations. New York, NY: Columbia Teachers College.

Furlong, M.J., Fullchange, A., \& Dowdy, E. (in press). Effects of mischievous responding on the results of school-based mental health screening: I love rum raisin ice cream, really I do! School Psychology Quarterly.

Furlong, M.J., O’Brennan, L.M., \& You, S. (2011). Psychometric properties of the Add Health School Connectedness Scale for 18 sociocultural groups. Psychology in the Schools, 48, 986-997. doi:10.1002/pits.20609

Furlong, M.J., You, S., Renshaw, T.L., Smith, D.C., \& O’Malley, M.D. (2014). Preliminary development and validation of the Social and Emotional Health Survey for secondary students. Social Indicators Research, 117, 1011-1032. doi:10.1007/s11205-013-0373-0

Furrer, C., \& Skinner, E. (2003). Sense of relatedness as a factor in children's academic engagement and performance. Journal of Educational Psychology, 95, 148-162. doi:10.1037/0022-0663.95.1.148

Goodman, R. (1997). The Strengths and Difficulties Questionnaire: A research note. Child Psychology \& Psychiatry \& Allied Disciplines, 38, 581-586. doi:10.1111/j.1469-7610.1997.tb01545.x

Gratis, M.N. (2013). Are family communication and school belonging protective factors against depressive symptoms in homeless youth in Toronto? Canadian Journal of Community Mental Health, 32, 75-83. doi:10.7870/cjcmh-2013-034

Greenspoon, P.J., \& Saklofske, D.H. (2001). Toward an integration of subjective well-being and psychopathology. Social Indicators Research, 54, 81-108. doi:10.1023/A:1007219227883

Huebner, E.S. (1994). Preliminary development and validation of a Multidimensional Life Satisfaction Scale for children. Psychological Assessment, 6, 149-158. doi:10.1037/1040-3590.6.2.149

Huebner, E.S., Laughlin, J.E., Ash, C., \& Gilman, R. (1998). Further validation of the Multidimensional Students' Life Satisfaction Scale. Journal of Psychological Assessment, 16, 118-134.

Ito, A., Smith, D.C., You, S., Shimoda, Y., \& Furlong, M.J. (2015). Validation and utility of the social emotional health survey-secondary for Japanese students. Contemporary School Psychology, 19, 243252. doi:10.1007/s40688-015-0068-4

Kelly, R.M., Hills, K.J., Huebner, E.S., \& McQuillin, S. (2012). The longitudinal stability and dynamics of group membership in the dual-factor model of mental health: Psychosocial predictors of mental health. Canadian Journal of School Psychology, 27, 337-355. doi:10.1177/0829573512458505 
Kessler, R.C., Aguilar-Gaxiola, S., Alonso, J., Chatterji, S., Lee, S., Ormel, J., Wang, P.S. (2009). The global burden of mental disorders: An update from the WHO World Mental Health (WMH) surveys. Epidemiologia e Psichiatria Sociale, 18, 23-33. doi:10.1017/S1121189X00001421

Keyes, C.L.M. (2005). Mental illness and/or mental health? Investigating axioms of the Complete state model of health. Journal of Consulting and Clinical Psychology, 73, 539-548. doi:10.1037/0022-006X.73.3.539

Kia-Keating, M., \& Ellis, B.H. (2007). Belonging and connection to school in resettlement: Young refugees, school belonging, and psychosocial adjustment. Clinical Child Psychology and Psychiatry, 12, 29-43. doi:10.1177/1359104507071052

Kim, E., Dowdy, E., \& Furlong, M.J. (2014). An exploration of using a dual-factor model in school-based mental health screening. Canadian Journal of School Psychology, 29, 127-140. doi:10.1177/0829573514529567

Kim, E., Dowdy, E., Furlong, M., \& You, S. (2016). Mental health profiles and quality of life outcomes among Korean adolescents. Manuscript under review.

Kim, E.K., Furlong, M.J., Ng, Z.J., \& Huebner, E.S. (in press). Child well-being and children's rights: Balancing positive and negative indicators in assessments. In S. Hart \& B. Nastasi (Eds.), International handbook on child rights in school psychology. New York, NY: Springer.

Lee, S., You, S., \& Furlong, M.J. (2015). Validation of the Social Emotional Health Survey for Korean school students. Child Indicators Research, 52, 349-362. doi:10.1007/s12187-014-9294-y

Lester, L., \& Cross, D. (2015). The relationship between school climate and mental and emotional well-being over the transition from primary to secondary school. Psychology of Well-being, 5(9). doi:10.1186/s13612-015-0037-8

Lester, L., Waters, S., \& Cross, D. (2013). The relationship between school connectedness and mental health during the transition to secondary school: A path analysis. Australian Journal of Guidance and Counseling, 23, 157-171. doi:10.1017/jgc.2013.20

Libbey, H.P. (2007). School connectedness: Influence above and beyond family connectedness. (Dissertation). Available from Proquest Dissertations and Theses database. (UMI No. 3287822)

Manassis, K., Wilansky-Traynor, P., Farzan, N., Kleiman, V., Parker, K., \& Sanford, M. (2010). The feelings club: Randomized controlled evaluation of school-based CBT for anxious or depressive symptoms. Depression and Anxiety, 27, 945-952. doi:10.1002/da.20724

McNeely, C., Nonnemaker, J., \& Blum, J. (2002). Promoting school connectedness: Evidence from the National Longitudinal Study of Adolescent Health. Journal of School Health, 72, 138-147. doi:10.1111/j.1746-1561.2002.tb06533.x

Moore, S.A., Widales-Benitez, O., \& Carnazzo, K.W., Kim, E.K., Moffa, K., \& Dowdy, E. (2015). Conducting universal complete mental health screening via student self-report. Contemporary School Psychology, 19, 253-267. doi:10.1007/s40688-015-0062-x

Muthén, L.K., \& Muthén, B.O. (1998-2013). Mplus user's guide (6th ed.). Los Angeles, CA: Muthén \& Muthén.

Pallant, J. (2013). SPSS Survival Manual: A step by step guide to data analysis using IBM SPSS (5th ed.). New York, NY: Open University Press.

Pennell, C., Boman, P., \& Mergler, A. (2015). Covitality constructs as predictors of psychological wellbeing and depression for secondary school students. Contemporary School Psychology, 19, 276-285. doi:10.1007/s40688-015-0067-5

Pittman, L.D., \& Richmond, A. (2007). Academic and psychological functioning in late adolescence: The importance of school belonging. The Journal of Experimental Education, 75, 270-290. doi:10.3200/JEXE.75.4.270-292

Rushkin, V., Jones, S., Vermeiren, R., \& Schwab-Stone, M. (2008). The Strengths and Difficulties Questionnaire: The self-report version in American urban and suburban youth. Psychological Assessment, 20, 175-182. doi:10.1037/1040-3590.20.2.175

Sargent, J., Williams, R.A., Hagerty, B., Lynch-Sauer, J., \& Hoyle, K. (2002). Sense of belonging as a buffer against depressive symptoms. Journal of the American Psychiatric Nurses Association, 8, 120-129. doi:10.1067/mpn.2002.127290 
Sawatzky, R., Ratner, P.A., Johnson, J.L., Kopec, J.A., \& Zumbo, B.D. (2009). Sample heterogeneity and the measurement structure of the Multidimensional Students' Life Satisfaction Scale. Social Indicators Research, 94, 273-296. doi:10.1007/s11205-008-9423-4

Seligson, J., Huebner, E.S., \& Valois, R.F. (2003). Preliminary validation of the Brief Multidimensional Students' Life Satisfaction Scale (BMSLSS). Social Indicators Research, 61, 121-145. doi:10.1023/A:1021326822957

Shochet, I., Dadds, M., Ham, D., \& Montague, R. (2006). School connectedness is an underemphasized parameter in adolescent mental health: Results of a community prediction study. Journal of Clinical Child \& Adolescent Psychology, 35, 170-179. doi:10.1207/s15374424jccp35

Stevanovic, D., Urbán, R., Atilola, O., Vostanis, P., Singh Balhara, Y.P., Avicenna, M., Petrov, P. (2015). Does the Strengths and Difficulties Questionnaire-Self Report yield invariant measurement cross different nations? Data from the International Child Mental Health Study Group. Epidemiology and Psychiatric Sciences, 24, 323-334. doi:10.1017/S2045796014000201

Suldo, S.M., \& Shaffer, E.J. (2008). Looking beyond psychopathology: The dual-factor model of mental health in youth. School Psychology Review, 37, 52-68.

Tabachnick, B.G., \& Fidell, L.S. (2013). Using multivariate statistics (6th ed.). Boston, MA: Pearson Education.

Venning, A., Wilson, A., Kettler, L., \& Eliott, J. (2013). Mental health among youth in South Australia: A survey of flourishing, languishing, struggling, and floundering. Australian Psychologist, 48, 299-310. doi:10.1111/j.1742-9544.2012.00068.x

Vieno, A., Perkins, D., Smith, T., \& Santinello, M. (2005). Democratic school climate and sense of community in school: A multilevel analysis. American Journal of Community Psychology, 36, 327-341. doi:10.1007/s10464-005-8629-8

World Health Organization. (2014). Young people: Health risks and solutions (Fact sheet No. 345). Geneva, Switzerland: Author.

You, S., Furlong, M.J., Felix, E., \& O’Malley, M. (2015). Validation of the social and emotional health survey for five sociocultural groups: Multigroup invariance and latent mean analyses. Psychology in the Schools, 52, 349-362. doi:10.1002/pits.21828

You, S., Ritchey, K., Furlong, M.J., Shochet, I., \& Boman, P. (2011). Examination of the latent structure of the Psychological Sense of School Membership Scale. Journal of Psychoeducational Assessment, 29, 225-237. doi:10.1177/0734282910379968 